\title{
Study of Thickness Effect on Fracture Toughness of High Grade Pipeline Steel
}

\author{
Hua ZHANG ${ }^{1,2, a,{ }^{*}}$, Hong ZHANG ${ }^{1, \mathrm{~b}}$, Xinwei ZHAO ${ }^{2, \mathrm{c}}$,Yalong $\mathrm{WANG}^{2, \mathrm{~d}}$ and $\mathrm{Na}^{2}{ }^{2 . \mathrm{e}}$ \\ ${ }^{1}$ China University of Petroleum-Beijing, Beijing 102249, China \\ ${ }^{2}$ Tubular Goods Research Institute of CNPC, Xi'an 710077,China \\ azhanghua011@cnpc.com.cn, bhzhang@cup.edu.cn, ${ }^{\mathrm{c}}$ zhaoxinwei001@cnpc.com.cn, \\ dina011@cnpc.com.cn, ${ }^{\mathrm{e}}$ wangyalong001@enpc.com.cn
}

\begin{abstract}
The critical fracture toughness decreases when thickness of specimens increases and stress-strain field in crack tip start changing to plane strain state from plane stress state. In this paper, fracture toughness tests were carried. Based on the analysis of stress-strain field in crack tip and fracture toughness test results, a fracture toughness-thickness empirical model was established and the plane strain fracture toughness and critical thickness of X80/X100 were calculated. Then the validity of the empirical model was discussed and verified. The analytical results indicate that the safety of thick wall pipelines is worth of attention.
\end{abstract}

\section{Introduction}

In fracture mechanics, when stress intensity factor in crack tip is equal to the material fracture toughness, crack will start to grow. That means fracture toughness of material can forecast the remaining strength of a component with an initial crack. Although fracture toughness is material inherent attribute, for the same material, different fracture toughness values was determined in different tests as test conditions (temperature, loading rate, et al) and specimen size are different. Of all the influence factors for fracture toughness test, specimen thickness is a most important factor.

Because there are amounts of oil and gas pipeline in the world, so cracks existing in some pipes body are almost inevitable. Stress in crack tip varies as pipe thickness is different. As thickness increases, stress-strain field in crack tip start changing to plane strain state from plane stress state, which means crack tip is in tension state in all three directions and the plastic zone will be limited in a small scope. So critical fracture toughness will decreases when pipe thickness increases in plane strain state, and brittle fracture is prone to happen, which is much more dangerous compared with ductile fracture.

In Chinese, pipe with high steel grade, large diameter and thick wall have been developing all the time. For pipes with high steel grade and thick wall which have been

* Corresponding author:zhanghua011@enpc.com.cn 
widely used, studies are focusing on whether fracture toughness has reached plane strain state or not. Fracture toughness tests of X80 pipeline steel that has been widely used and industrial trial -produced X100 pipeline steel with different wall thickness- were conducted and carefully analyzed in this paper. Based on analysis of stress field in crack tip, plane strain fracture toughness forecasting model was built, which is used to forecast whether the pipe thickness meets the plane strain condition or not.

\section{Thickness Effect of Fracture Toughness}

For component with a crack and external load, stress intensity factor $\mathrm{K}_{\mathrm{I}}$ (take I mode crack as example) is a mechanics parameter to describe stress field in crack tip. $\mathrm{K}_{\mathrm{I}}$ would increase if external loading increases. When $\mathrm{K}_{\mathrm{I}}$ increases to a critical value, the crack in component begins to grow. This critical value is called fracture toughness $\mathrm{K}_{\mathrm{C}}$ or $\mathrm{K}_{\mathrm{IC}}$, which represents the material's ability to resist unstable propagation of crack. Fracture toughness $\mathrm{K}_{\mathrm{C}}$ or $\mathrm{K}_{\mathrm{IC}}$ is inherent attribute of a material. The difference is that $\mathrm{K}_{\mathrm{C}}$ is fracture toughness under plane stress state, which would be influenced by thickness of plate or test specimen. When specimen thickness increased, fracture toughness tends to be a stable and lowest value, which would not be influence by thickness. This value is called $\mathrm{K}_{\mathrm{IC}}$ or plane strain fracture toughness. $\mathrm{K}_{\mathrm{IC}}$ is the real material constant, which reflects the material's ability to prevent crack extension.

\section{Facture Toughness Tests of Pipeline Steel}

\subsection{Test Materials}

X80 and X100 specimens were separately sampled from $\varnothing 1219 \times 26.4 \mathrm{~mm}$ and $\varnothing 1219$ $\times 23.5 \mathrm{~mm}$ longitudinal submerged arc welding pipe. Mechanical properties of the X80 and X100 pipes were shown in Table 1.

Table 1 mechanical properties of test materials.

\begin{tabular}{|c|c|c|c|}
\hline \multirow{2}{*}{ Material } & Tensile strength & Yield strength & Elongation \\
\cline { 2 - 4 } & $\mathrm{R}_{\mathrm{m}}[\mathrm{Mpa}]$ & $\mathrm{R}_{\mathrm{p} 0.2[\mathrm{Mpa}]}$ & {$[\%]$} \\
\hline X80 & 665 & 556 & 22 \\
\hline X100 & 786 & 717 & 19 \\
\hline
\end{tabular}

\subsection{Test Results}

In order to work out the thickest test specimen, CT(compact tensile ) specimens were used. For pipelines, axial crack is most dangerous because the largest stress on pipe locate in hoop direction. So the direction of precast crack in specimen was parallel to pipe axial direction. For X80 pipe material, specimen thickness was 25, 22, 20, 18, 16 and 14, 12, 10, 8, $6 \mathrm{~mm}$ respectively. The thickest X100 specimen was $22 \mathrm{~mm}$. There are 3 specimens for each set (grouped by thickness) of sample. Tests were carried out in accordance with the provisions of GB/T 21143-2007 $7^{[2]}$. The results are shown in Table 2, in which test results is average value of three specimens. 
Table 2 fracture toughness $\mathrm{k}_{\mathrm{c}}$ test results.

\begin{tabular}{|c|c|c|c|c|c|c|c|c|c|c|}
\hline Thickness $[\mathrm{mm}]$ & 6 & 8 & 10 & 12 & 14 & 16 & 18 & 20 & 22 & 25 \\
\hline $\mathrm{X} 80{\left[\mathrm{MPa} . \mathrm{m}^{0.5}\right]}^{0}$ & 59.0 & 57.9 & 62.3 & 61.1 & 61.7 & 59.8 & 67.3 & 65.6 & 62.8 & 63.6 \\
\hline $\mathrm{X} 100\left[\mathrm{MPa} \cdot \mathrm{m}^{0.5}\right]$ & 69.5 & 76.1 & 75.5 & 75.1 & 75.5 & 78.4 & 78.6 & 83.0 & 81.5 & $/$ \\
\hline
\end{tabular}

Overall, fracture toughness of X100 is bigger than X80. Fracture toughness reaches to the biggest value when the specimen thickness is $18 \mathrm{~mm}$ for X80 and $20 \mathrm{~mm}$ for X100. After peak value, fracture toughness begins to gradually decrease with increase of wall thickness. Before reaching to the biggest value, fracture toughness value has a platform which is measured with smaller thickness specimens.

\subsection{Fractographic Features Analysis}

Fracture SEM photographs of X80 and X100 sample with different thickness are shown in Fig. 1 and Fig.2. It is found that all fractures are ductile fracture. There are many dimples with different size and non-uniform distribution on the fracture section. So in the thickness range of all the tests, material has not yet to embody the characteristics of embrittlement, and the crack propagation region presents plastic state. A tongue shape crack propagation region existed in fracture section, which is shown in Fig.3. In the figure, B is the thickness of the original sample, and $\mathrm{A}$ is the width of crack propagation in experiment process. Due to constraint effect in thickness direction, central sample material is in three-dimensional tensile stress state. So middle part of the sample begun to crack firstly. With the increase of external load, the region reaching to critical stress intensity factor in thickness direction became larger, but the crack speed in central part of specimen was the biggest. So the fracture section shows a tongue shape.

\subsection{Fracture Toughness-thickness Empirical Model}

The shape of crack tip plastic zone is shown in Fig.4. For stress state in crack tip, the ratio of plastic zone to thickness is an important coefficient. If the values of plastic zone size and specimen thickness are in same order of magnitudes, which means $r_{p} / B$ tends to be 1 , the plane stress state is dominant. In order to make sure most of the material in thickness direction is in stress state of plane strain, $r_{p} / B$ must be significantly less than 1 , which means material near surface in plane stress state in thickness direction just be a small part through thickness section. Tests confirmed that when $r_{p} / B$ was about 0.025 , then stress state when crack happens was typical plane strain $^{[3]}$.
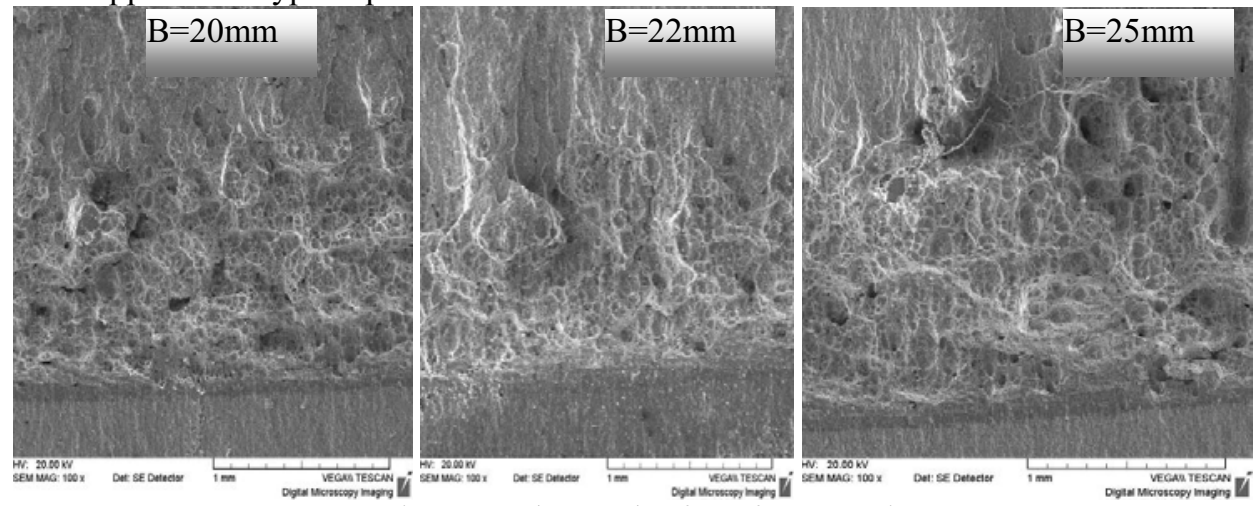

Fig.1 SEM photographs of X80 fracture section. 


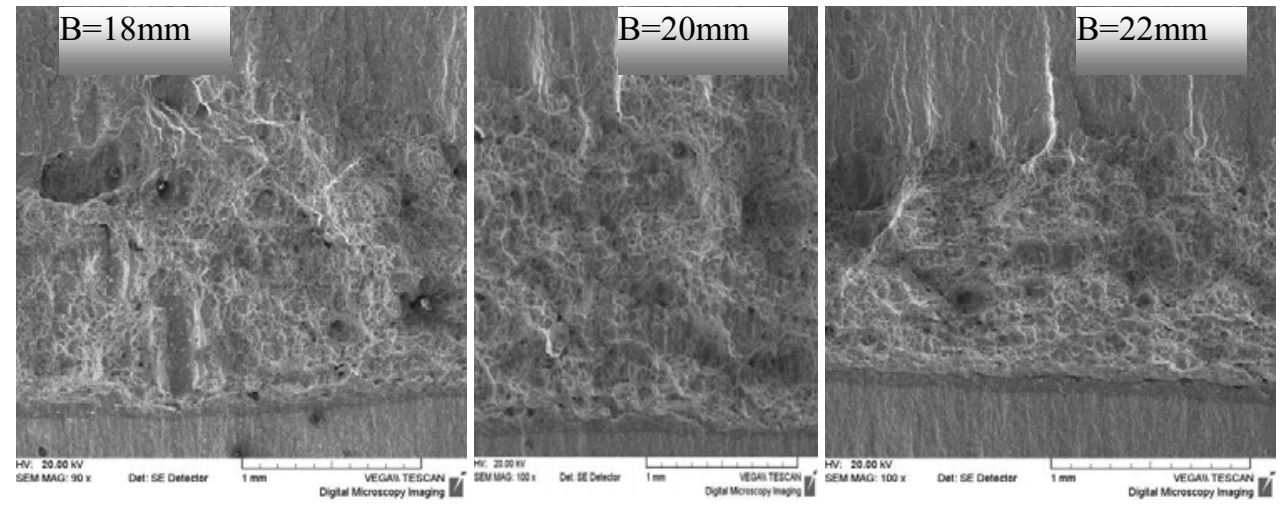

Fig.2 SEM photographs of X100 fracture section

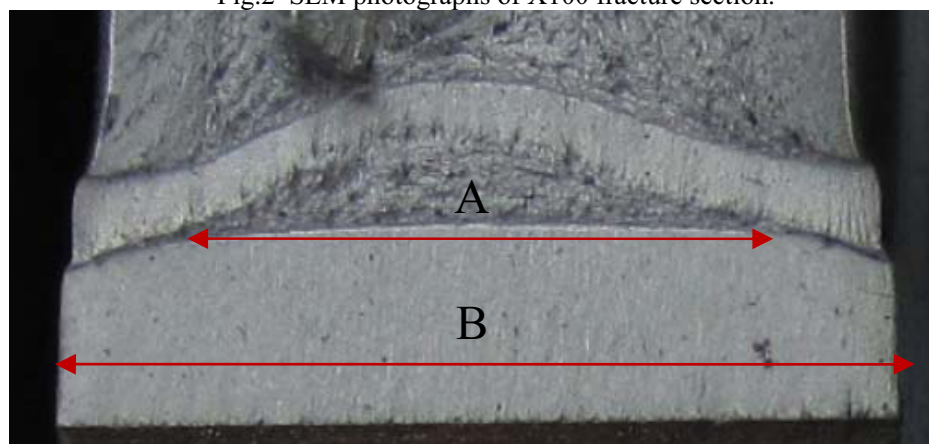

Fig.3 Tongue shape in fracture section of fracture toughness specimen.

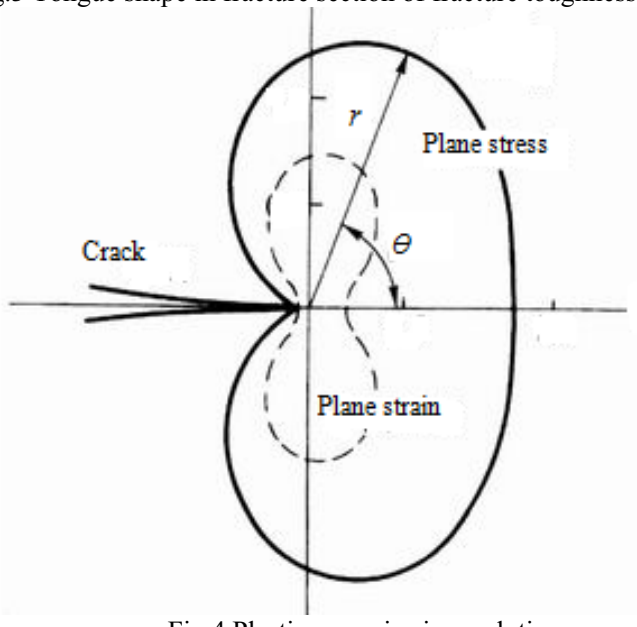

Fig.4 Plastic zone size in crack tip.

Based on the elastic solution of plane stress state, crack tip plastic zone radius $(\theta=0)$ can be expressed as

$$
r_{p}=\frac{\mathrm{K}_{\mathrm{I}}{ }^{2}}{2 \pi{\sigma_{\mathrm{ys}}}^{2}}
$$

Where $r_{p}$ is the radius of plastic zone size, $\sigma_{\mathrm{ys}}$ is yield strength, $\mathrm{K}_{\mathrm{I}}$ is stress intensity factor.

An obvious problem in this formula is that when crack tip stress exceeds the material yield strength, the exceeded load must be bore by material outside the hypothesis boundary. 
So the plastic zone will larger than the expression of Eq.(1).In spite of great progress of working in determining true size and shape of plastic zone, but there is still no perfect theory which can give a satisfactory description to the shape of plastic zone. The biggest radius of plastic zone locates in specimen surface. From surface to specimen center, as crack tip stress field is changing to plane strain state from plane stress state, and the size of plastic zone is also gradually decreasing. For the specimen, the overall plastic zone is smaller than that decided by surface plastic zone radius. So if surface plastic zone is used as specimen plastic zone, it has already amended the size by a correction factor more than 1 .

On other hand, the theory of $\mathrm{K}_{\mathrm{IC}}$ was established on the basis of elastic mechanics. So in situation of fitness for linear elastic fracture mechanics, which means plastic zone is much less than crack size, then plastic correction is not necessary. If plastic zone is not small compared with crack size, then expression of $\mathrm{K}$ based on elastic mechanics should be limited to apply. Plastic zone radius determined by linear elastic mechanics and von Mises yield criterion is used to characterize the plastic zone in plane stress state in this paper. As mentioned above, when $r_{p} / \mathrm{B}=0.025$, then the specimen is in stress state of plane strain.

That means the plastic zone size radius is only $1 / 40$ of the specimen thickness. In this case, the plastic zone is very small compared with specimen size and Eq.(1) can be used.

In case of $r_{p} / \mathrm{B}=0.025$, plane strain fracture toughness $\mathrm{K}_{\mathrm{IC}}$ is substituted for $\mathrm{K}_{\mathrm{I}}$ in Eq.(1), then the critical thickness of plane strain can be expressed as

$$
\mathrm{B}_{\mathrm{IC}}=6.4 \frac{\mathrm{K}_{\mathrm{IC}}{ }^{2}}{\sigma_{\mathrm{ys}}{ }^{2}}
$$

Where $\mathrm{B}_{\mathrm{IC}}$ is the critical thickness of plane strain state.

The effect of thickness on fracture toughness was analyzed by Anderson ${ }^{[4]}$ based on existing experimental data. In his study, it was reasonable that $\mathrm{K}_{\mathrm{IC}}$ linearly decreased with thickness increase. In other studies ${ }^{[5]}$, the relationship between $K_{C}$ and thickness was expressed as

$$
\mathrm{K}_{\mathrm{C}}=\xi \times t^{1 / 2} e^{-k t}+\mathrm{K}_{\mathrm{IC}}\left(1-e^{-k t}\right)
$$

Where $\xi$ and $k$ were material constants, $t$ was thickness. This equation is applicable to material of TC4 titanium alloy.

Through calculation of Eq.(3), point of fracture toughness-thickness can be got as shown in Fig.5. Linear pattern was used to fit the points between maximum value of $\mathrm{K}_{\mathrm{C}}$ to value close to plane strain fracture toughness, and the fitting curve is shown in Fig.5. It shows that linear fitting is suitable for this curve segment as the value of correlation coefficient is 0.998.

But according to the Eq. (3), $\mathrm{K}_{\mathrm{C}}$ would increase from 0 with thickness increase before reaching to the maximum value. While according to the test data shown in Table 1, the fracture toughness of pipeline steel $\mathrm{K}_{\mathrm{C}}$ has not decreased with wall thickness increase before reaching to the maximum value, and there is a platform in the curve. Some material would accord with this law mentioned in the literature [3]. So for pipeline steel, the error is large when fitting the relationship between fracture toughness and thickness.

Experiment data of X80 pipeline steel after fracture toughness reached to the maximum value (data of thickness larger than $18 \mathrm{~mm}$ ) were used and fitted by linear pattern, the linear relationship between fracture toughness and specimen thickness can be expressed as

$$
\mathrm{K}_{\mathrm{C}}=-0.565 \times \mathrm{B}+76.8
$$

Let $\mathrm{K}_{\mathrm{C}}=\mathrm{K}_{\mathrm{IC}}, \mathrm{B}=\mathrm{B}_{\mathrm{IC}}$, then 


$$
\mathrm{K}_{\mathrm{IC}}=-0.565 \times \mathrm{B}_{\mathrm{IC}}+76.8
$$

$\mathrm{K}_{\mathrm{IC}}$ is $48.9 \mathrm{MPa} \cdot \mathrm{m}^{0.5}$ and $\mathrm{B}_{\mathrm{IC}}$ is $49.4 \mathrm{~mm}$ by solving Eq.(2) and Eq.(5). Same method was used to calculate the plane strain fracture toughness and critical thickness of X100.The $\mathrm{K}_{\mathrm{IC}}$ value is $49 \mathrm{MPa} \cdot \mathrm{m}^{0.5}$ and $\mathrm{B}_{\mathrm{IC}}$ is $62.7 \mathrm{~mm}$. Because wall thickness of X100 pipeline steel is thin relatively, and the thickest specimen is only $22 \mathrm{~mm}$, so there is only one point after peak point in the fracture toughness-thickness curve. That means the error of this forecasting model for X100 may be big, and the result is for reference only.

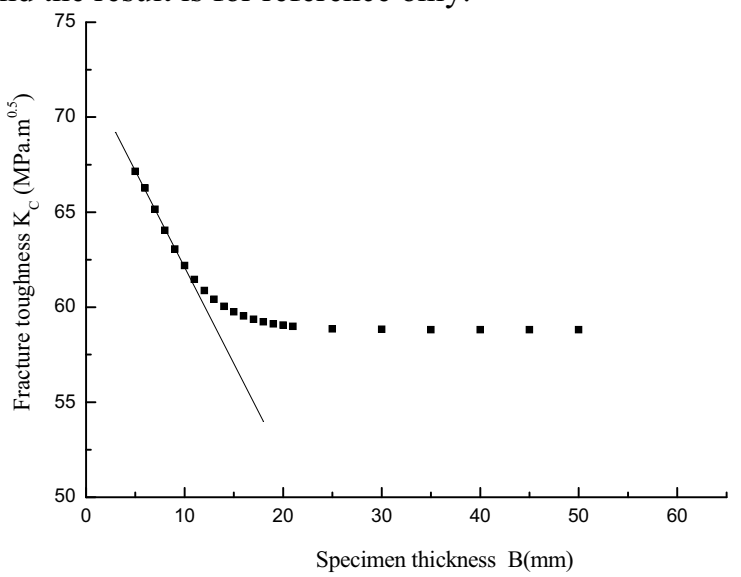

Fig.5 Linear fitting and validation.

\subsection{Analysis and Validation of the Empirical Model}

Experiment data of TC4 titanium alloy in literature $[5,6]$ was used to validate this model. $\mathrm{K}_{\mathrm{IC}}$ test result in the literature was $58.8 \mathrm{MPa} \cdot \mathrm{m}^{0.5}$, and the forecasted result with our model is 54.6 MPa. ${ }^{0.5}$. The error is just $7.2 \%$. The critical thickness forecasted by this model is $22.9 \mathrm{~mm}$. But this parameter is unknown in the literature. From the forecasted curve (the forecasted points in Fig.5), it is found that when thickness is more than $20 \mathrm{~mm}$, the fracture toughness has slight difference, which means that the stress state in crack tip is nearly plane strain state.

In literature [7], ratio of plane strain width to specimen thickness is an important parameter. $\mathrm{K}_{\mathrm{C}}$ gradually tends to $\mathrm{K}_{\mathrm{IC}}$ when this ratio increases to $100 \%$. As shown in Fig.3, crack tip does not propagate in the same speed, but faster in central and lower in surface. So the tongue shape formed in fracture section. After analyzing stress-strain field in crack tip, it is found that because central part of the sample was in three-dimensional tensile stress state, so this part begun to crack firstly. At the same time, plastic development is limited and brittle fracture is prone to happen in the central part. As load increases, crack tip width which reaches critical value of fracture strength becomes larger, but central crack propagates in the fastest speed.

The crack front width (A in Fig.3) was analyzed for both X80 and X100 specimens. When dividing crack width in central crack front divide by the specimen thickness, it is found that for wall thickness larger than $14 \mathrm{~mm}$, ratio of crack width to thickness increases when thickness increases. Linear law is obtained as shown in Fig.6.

If crack front width is used to characterize the width of plane strain, then the specimen is totally in stress state of plane strain when the ratio of crack width to thickness reaches to 1 . Although this is impossible, if the ratio reaches a certain value, the specimen can be regarded as be in total plane strain state. 
As shown in Fig.6, it can be seen that when thickness is bigger than $14 \mathrm{~mm}$, the linear relationship can be obtained between ratio of crack width to thickness and thickness itself. This ratio increases as thickness increases. When thickness is less than $14 \mathrm{~mm}$, no obvious relationship can be found. The possible reason is that in thin specimen test, proportion of plane strain crack is small. In thin specimen crack, Plane stress crack dominates the test, so the crack extension law is different from that of plane strain.

Test results of thickness more than $16 \mathrm{~mm}$ were used, the linear relationships for both X80 and X100 were obtained between crack width to thickness ratio and thickness. Taking the width-to-thickness ratio up to $100 \%$ as criterion of plane strain, it is found that the critical thickness of $\mathrm{X} 80$ is $45 \mathrm{~mm}$, and that of $\mathrm{X} 100$ is $38.7 \mathrm{~mm}$.

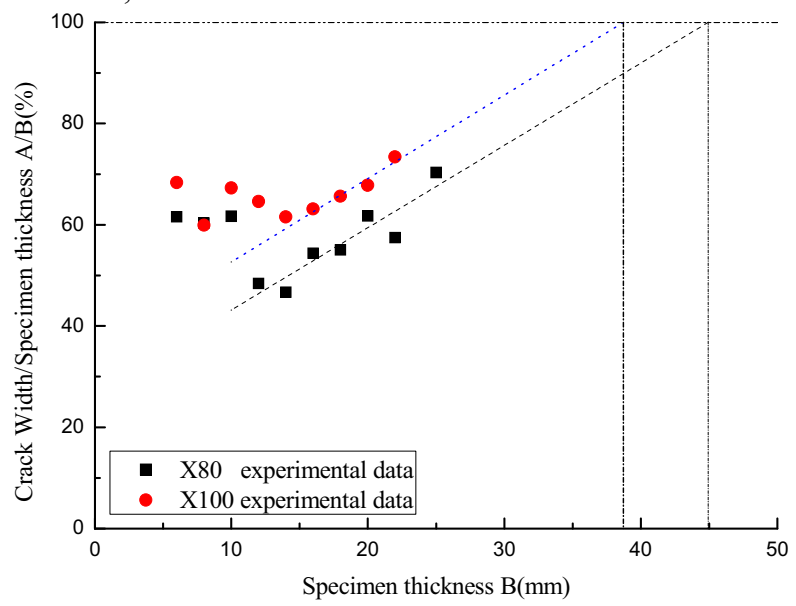

Fig.6 Relationship of crack width-to-thickness ratio and specimen thickness.

For $\mathrm{X} 80$, it can be seen that the difference of plane strain critical thickness calculated from our model and from width-to-thickness ratio model in literature [7] is very little $(4.7 \mathrm{~mm})$. But for X100, the difference is very large. The possible reason is that in our tests, only one point was obtained after peak point in fracture toughness-thickness curve. So the error will be big if the test data is limited when using our model to estimate the plane stress fracture toughness or critical thickness.

Linear fitting was adopted for both the above two kinds of material. But in case of thickness increase, especially the thickness is nearly plane strain condition, the fracture toughness and specimen thickness has not shown a simple linear relationship. Because even if the specimen is thick enough, it cannot completely reach ideal plane strain state, so the ratio of A/B can only be infinitely close to 1 , but not to be 1 . So calculated critical thickness will be less than actual value, but it can infinitely close to it. From the test results, it can be confirmed that this representation is reasonable, and the model proposed in this paper has been validated.

\section{Conclusions and Suggestions}

In the second west to east gas pipeline project, the thickness of bends and fittings is more than $50 \mathrm{~mm}$. From analysis above, the possibility of the brittle fracture does exist. So the safety of thick wall pipelines is worth of attention. On the other hand, because wall thickness of general X80 pipe is usually not so thick, and the critical thickness of plane strain fracture toughness is nearly $50 \mathrm{~mm}$. So characteristics of the plane strain can't appear in actual X80 pipeline and the crack resistance is not determined by $\mathrm{K}_{\mathrm{IC}}$. In such cases, the actual fracture toughness is usually higher than $\mathrm{K}_{\mathrm{IC}}$, which means that if $\mathrm{K}_{\mathrm{IC}}$ is used to estimate critical crack 
size and residual strength of a component, then conservative result will be obtained. Especially when fracture stress intensity factor is much bigger than extension stress intensity factor, the criterion of $\mathrm{K}_{\mathrm{IC}}$ might be too conservative. So for a specific case, specimen of appropriate size and thickness should be used to determine the fracture toughness.

\section{References}

1. Mc Clintock F, Argon A. Mechanical Behavior of Materials, Addison-Wesley Publishing Company, 1968.

2. GB/T 21143-2007. Metallic materials-Unified method of test for determination of quasistatic fracture toughness. 2007.

3. Brock D, translated by Wang KR, He MY, Gao H. Elementary Engineering Fracture Mechanics, Beijing Science Press, 1980.

4. William Anderson,W. Some designer-oriented view on brittle fracture. Battelle Northwest Rept.SA-2290,1969.

5. Yang JY, Zhang X. Research on Thickness Effect on Cracked Plate Fracture Toughness. Journal of Mechanical Strength, 2005, 27( 5) : 672-680.

6. Yang JY, Zhang X, Zhang M. Theory and Application on Thickness Effect on Cracked Plate Fracture Toughness. Journal of Mechanical Engineering, 2005,41(11):32-42.

7. Marc Andre Meyers, Krishan Kumar Chawla. Mechanical Behavior of Materials, Cambridge University Press,2009. 